\title{
Teodiceas apocalípticas Aportes para una sociodicea
}

\author{
César O. Carbullanca N.* \\ Pontificia Universidad Católica de Chile (Chile) \\ ccarbull@uc.cl
}

\begin{abstract}
Resumen
A partir de la formulación weberiana de teodicea, esta pesquisa sostendrá la centralidad de la cuestión de la teodicea para la religión. No obstante, la definición weberiana de teodicea presenta problemas para su aplicación a textos de la antigüedad, pues, a juicio de Sarot, la teodicea sería un fenómeno moderno que marcaría una nueva manera de pensar sobre el mal. A partir de lo cual, el artículo pasa revista a diversas teodiceas mostrando la variedad de respuestas, colocando en evidencia un panorama distinto al presentado por Weber y Berger. La pregunta sobre el porqué del sufrimiento que hace el visionario y profeta trasciende los modos habituales de pensar la existencia del sufrimiento y del mal en un tiempo específico para abrirse a la interrogación y protesta contra todo sufrimiento llevando a pensar de nuevo la relación de Dios en el mundo, de tal manera que más que hablar de una justificación de Dios por el sufrimiento y el mal en el mundo, la teodicea interroga y desafía al creyente y a Dios para buscar otras respuestas.
\end{abstract}

Palabras claves: religión; sufrimiento; teodicea; apocalíptica; sentido.

\section{Apocalyptic theodicy \\ Contributions for a sociodicea}

\section{Summary}

From the weberian formulation of theodicy, this inquiry will hold the centrality of the question of theodicy for religion. However, the weberian definition of theodicy presents problems for its application to texts of antiquity, because, according to Sarot, theodicy would be a modern phenomenon that would mark a new way of thinking about evil. From which the article reviews various theodicy showing the variety of responses, highlighting a different picture than that presented by Weber and Berger. The question about the suffering of the visionary and the prophet transcends the habitual ways of thinking about the existence of suffering and evil at a specific time to be open to interrogation and protest against all suffering, leading us to think again about God's relationship in the world, in such a way that rather than talking about a justification of God for suffering and evil in the world, theodicy interrogates and challenges the believer and God to look for other answers.

Key words: religion; suffering; theodicy; apocalyptic; meaning.

* Doctor en Teología Bíblica por la Pontificia Universidad de Comillas (Madrid). Docente e investigador en la Pontificia Universidad Católica de Chile. Miembro asociado del Centro de Estudios de la Religión UC.

Este artículo es parte del proyecto FONDECYT Regular 2018 - Nº 280788. 


\section{TEODICEA Y SOCIOLOGÍA DEL MAL}

Diversos autores como Morgan \& Wilkinson (2001), K. H. Wolff (1969), V. Das (1997), C. Conradi (2016) y R. Ramos han atendido al "problema moderno de la sociodicea" (2003: 224). En el caso de Morgan \& Wilkinson se quejan acerca de la poca atención que posee la teodicea para la sociología: "la experiencia vivida de la adversidad y sufrimiento ha sido raramente el foco explícito para el análisis sociológico" (2001: 200) y citando a Bryan Turner afirma:

...cualquier sociología que lucha contra el dolor y muerte, accidentes, desgracia, inequidad e injusticia en la vida social debe necesariamente encontrarse con el problema de la teodicea...el problema de la social teodicea está presente en cualquier sociología que intenta levantar la cuestión del origen y causa de la inequidad entre los hombres. (citado en Morgan \& Wilkinson, 1996: 170-171)

En opinión de Veena Das esto refleja una fractura característica entre la racionalidad moderna y la ética: "el siglo de los genocidios... el sufrimiento y el mal han sido impuestos en forma deliberada, y cuando la razón se desentiende de toda ética es incapaz de poner límites a la barbarie humana" (2008: 446-447). En otro lugar, argumentando esta afirmación, señala: "para la antropología social y sociología dar sentido al sufrimiento sigue siendo una tarea de primer orden" (Das, 2008: 437). No son pocos los investigadores como C. Conradi que señalan que la confrontación con el mal ha sido a menudo "bypassed por la sociología" (2016: 465). Por otra parte, es ya antiguo el prejuicio acerca de la incapacidad de las religiones para enfrentar el problema del mal, entendido como racionalización metafísico-doctrinal que, al hipostasiar el tema del mal, desplaza el verdadero problema de su erradicación de la sociedad humana. En este contexto, ¿es aún relevante el diálogo con las religiones para enfrentar el desafío del mal en la sociedad? Los clásicos estudios de M. Weber y P. Berger enseñan que, desde sus orígenes, la sociología ha recurrido al expediente de las religiones para comprender más cabalmente el modo y la dinámica de la lucha contra el mal en las sociedades.

Desde una perspectiva de los estudios bíblicos hay que decir que la investigación acerca de las teodiceas bíblicas, y más específicamente, de las teodiceas apocalípticas, es harto escaso y muestra vacíos serios, pero más grave aún, no hay conciencia del aporte que puede significar la milenaria reflexión sobre el sufrimiento que posee el judaísmo y el cristianismo para una contribución en la lucha contra el sufrimiento social. Desde una perspectiva histórica, los artículos de P. Sacchi (1990) y también J. 
Charlesworth (2003) son notables y ayudan a valorar la variedad de teodiceas bíblicas y apócrifas. Laato \& Moor (2003) en su estudio enumeran, solo en el mundo extra-bíblico, cuatro teodiceas, y en los textos bíblicos enumeran nada menos que diez tipos. En una visión de conjunto, Laato \& Moor (2003: xxix-xxx) logran sintetizar seis tipos distintos. Charlesworth señala ocho teodiceas solamente para escritos apocalípticos, y R. Price señala cinco tipos distintos de teodiceas para el Nuevo Testamento (1986: 309-315). Dicho esto, por un lado, los estudios se limitan en su mayoría a los textos bíblicos canónicos; y por otro, los estudios sobre teodicea apocalíptica carecen de un estudio sistemático. Valga esta breve enumeración para mostrar que la clasificación de Weber y Berger es parcial, pues no consideran el material aportado por textos apocalípticos, seudo-epigráficos y por el material literario descubierto en Qumrán para una comprensión más amplia de las teodiceas judías y cristianas. Esta ausencia es más notable pues a partir de estos estudios ha cambiado drásticamente nuestra actual visión tanto del judaísmo como del cristianismo en puntos sensibles para la teodicea.

El artículo pretende actualizar — en la medida de lo posible - la discusión sobre los imaginarios del sufrimiento o teodicea apocalíptica judeo-cristiana y su eventual aporte a una sociología del sufrimiento. Para lograr este objetivo, en primer lugar, discutirá el concepto weberiano de teodicea, asumido por Peter Berger (1967) y otros autores, señalando que las teodiceas que estudiaremos no reflejan el concepto weberiano pues estas no se entienden como racionalizaciones sino como imaginarios pragmáticos, socio-culturales, creados por grupos que generan relatos ficticios en función de erradicar o dar sentido a su experiencia de sufrimiento. Posteriormente, estudiaremos diversos textos apocalípticos judeo-cristianos de la antigüedad de grupos marginales, intentando delinear las características que presentan dichos textos. En este sentido, J. D. Crossan ha introducido una distinción importante sobre apocalíptica de grupos subalternos y populares que es necesario tener en cuenta:

el milenarismo de los escribas, propio de las clases subalternas, que todo lo que dio de sí fue, una serie de textos, sino el milenarismo popular, propio de la clase de los campesinos, que lo que dio de sí fueron acciones... el apocalipticismo era propio, de una y otra clase, pero en cada caso de manera diversa. (1994: 200)

Consideramos errada dicha distinción, más precisamente es un prejuicio elitista pues como podemos comprobar en Latinoamérica, campesinos iletrados generan textos como cancioneros populares, canto a lo divino, dichos sapienciales como refranes y adivinanzas, etc. Más aún, a 
diferencia de textos canónicos, los textos marginales poseen la característica del testimonio que responde a crisis existenciales lo cual explica el carácter pragmático que entrega identidad y sentido social. Así las cosas, el estudio asumirá operativamente la teodicea como la emergencia de un imaginario originado en una situación de crisis cultural, por grupos subalternos o marginales que llega a nosotros por medio de relatos los cuales presentan una nueva cultura, una nueva manera de vivir, creer y dar sentido a las catástrofes, sufrimientos e injusticias que acontecen a un pueblo en un determinado contexto. Propondremos que la cuestión de los imaginarios del sufrimiento (teodicea) en textos religiosos establece una vinculación con cuatro aspectos de un proceso de transformación cultural: a) la pregunta de las víctimas por el sentido del caos como elemento esencial de la respuesta; b) una crisis existencial c) una acción socio-literario terapéutica que pretende la superación del mal, y d) una auto-convocatoria social.

\subsection{Religión y Teodicea}

Weber intenta establecer la relación sobre las ideas religiosas y los intereses económicos, así como la influencia de los intereses materiales sobre las ideas religiosas. En su escrito La Ética protestante y el espiritu del capitalismo (2011), trata de la primera vertiente del problema mientras que en Sociología de la religión y en La ética económica de las religiones universales considera la segunda vertiente. En diversos momentos de su itinerario intelectual Weber abordará la cuestión de una sociología de la religión, de tal manera que definirá la religión en Ensayos sobre sociología de la religión como una "necesidad metafísica de encontrar un significado común a estas tensiones insalvables" (Weber, 1984a: 560) según esto, Weber, la necesidad metafísica es "la condición especifica de toda religión, de que el acontecer del mundo...es un proceso con sentido" (Weber, 1984a: 556), lo lleva a constatar que esta pretensión choca a cada momento con tensiones infranqueables, como el caos y la anomia de tal manera que:

Ese servicio de legitimación que la religión había de prestar al interés externo e interno de todos los dominadores, propietarios, vencedores, sanos, en suma felices, es la teodicea de la felicidad... está asentada en necesidad muy sólidas (farisaicas) de los hombres, y por ello fácilmente comprensible, aunque muchas veces sus efectos no sean debidamente atendidos. (Weber, 1997: 334)

Este proceso que se mostró primero como el habitual problema del sufrimiento injusto, a lo largo de la historia ha tendido a una progresiva devaluación del mundo, en cada caso, la religión ha dado un servicio de 
legitimación. En sus escritos póstumos Economia y sociedad Weber establece una relación central entre religión y teodicea:

En todas partes el problema está enlazado de alguna manera con los fundamentos determinantes del desarrollo religioso y de la necesidad de salvación. No con argumentos obtenidos de las ciencias naturales, sino en la incompatibilidad de una Providencia divina con la injusticia y con la imperfección del orden social... (Weber, 1997:192)

Weber comprende la teodicea como ideología (1978: 17), mencionando tres ideologías: el karma, el dualismo mazdeísta y la predeterminación del deus asconditus. La teodicea entendida como ideología trataría sobre la necesidad de salvación que está alimentada por la tensión entre incompatibilidad del concurso divino y la injusticia e imperfección del orden social, y en otro lugar subraya "las esperanzas de salvación dieron lugar a algún tipo de teodicea del sufrimiento" (Weber, 1998a: 240). Ciertamente, Weber emplea un concepto leibniziano de teodicea que presupone la modernidad aplicando dicho concepto a religiones premodernas. Las posiciones de M. Weber serán asumidas por P. Berger quien sostendrá la centralidad de la cuestión de la teodicea para la religión: "Nuestro propósito se ha logrado si hemos indicado la centralidad del problema de la teodicea para cualquier esfuerzo religioso para la conservación del mundo" (Berger, 1967: 80). De la misma manera Bowker comenta que para Weber "las religiones vierten sentido y explicación en las rendijas de la desigualdad y organizan sociedades para que sean una expresión viva de una teodicea determinada" (Bowker, 2006: xxviii). El problema del sufrimiento y, en general, de todas las incógnitas y sufrimientos del hombre, es una precondición de todas las religiones. Así, para M. Weber, P. Berger y Cl. Geertz establecerán en sus escritos una relación central entre religión y teodicea. Por ejemplo, Cl. Geertz describe la religión como sistema simbólico (ideológico) que genera concepciones de un orden general de existencia y los reviste a éstos con un alto grado de efectividad y realismo (Geertz, 2006: 89). A juicio de Geertz, el caos amenaza irrumpir en la vida social del hombre y éste constituyen a toda religión: "el desconcierto, el sufrimiento y la sensación de una paradoja ética insoluble son desafíos que toda religión aspira a dar respuesta" (Geertz, 2006: 97; Berger, 1967: 26.36). Geertz hablando de la teodicea señala: "la religión expresa el carácter ineludible de la ignorancia, del sufrimiento y de la injusticia en la experiencia humana" (Geertz, 2006: 104). 


\subsection{El Problema de la teodicea weberiana}

La comprensión weberiana de teodicea presenta diversos puntos problemáticos.

Un primer elemento discutible radica en que Weber aplica el concepto de teodicea de una manera anacrónica a la pregunta por el problema del sufrimiento humano en periodos pre-modernos. Como ha sido puesto en evidencia por M. Sarot, la teodicea sería "un fenómeno típicamente moderno" (Sarot, 2003: 21) que marcaría: "el surgimiento de un nuevo modo de pensar sobre el mal" (Sarot, 2003: 5) añadiendo: "sería equivocado usar el término teodicea para aproximaciones bíblicas u otras aproximaciones pre-modernas al mal...”. Por contraste, el concepto de teodicea usado por Weber y de sucesivos autores, está planteado en términos de un pensamiento lógico en función del teísmo que establece la incompatibilidad entre la existencia de un Dios bueno, poderoso, sabio y las imperfecciones del mundo histórico (Basinger, 1994: 89).

Un segundo elemento problemático radica en la cuestión epistemológica, relacionado con en el carácter racionalista que posee el planteamiento weberiano, que sostendría como finalidad de la teodicea la clausura en términos teóricos del problema del sufrimiento. Esta perspectiva contrasta con el carácter interrogativo, existencial y pragmático que diversos autores aprecian en los escritos bíblicos y apócrifos. Por cierto, opiniones como las de Putt (1997), E. Boase (2008) y J. Crenshaw (1983), que hablan de una anti-teodicea o teodicea de protesta no son aisladas, en palabras de Crenshaw:

los escritos de Israel a menudo revelan un conflicto entre estos que están contentos con una tradicional o convencional idea de Dios, y estos que han buscado una más profunda y más realista comprensión de lo que debía significar vivir con Dios en su propio tiempo y generación. (1983: 10)

Para B. Putt "la teodicea de Israel fue una teodicea de protesta" (1997: 463) mientras que para J. Bowker "para los profetas...a menudo se encuentran ellos mismos, no solo, contra mundum sino también contra fidem contra la prevalente comprensión de fe entre sus contemporáneos" (1970:10). En opinión de Charlesworth, las teodiceas "no fueron ni teoréticas ni abstractas, ellos (Israel) evolucionan a través de reflexiones sobre crisis sociales e históricas" (2003: 471). Hay que decir que se trata de reflexiones parciales, episódicas, en progreso; así la crisis del destierro, en opinión de E. Boase significó la emergencia de un nuevo imaginario, una nueva manera de ser ante el sufrimiento que constituye una "crisis existencial de Jerusalén" (2008: 450), de la misma manera en periodo 
post-exílico, se producen en Palestina diversas catástrofes nacionales y crisis de sentido en el judaísmo que conlleva una transformación cultural y que se aprecia en diversos escritos de la época.

Un tercer elemento discutible del concepto weberiano de teodicea es el presupuesto descontextualizado de una separación entre religión y sociedad. En la antigüedad, son las instituciones sociales, no las iglesias, las que formulan míticamente las preguntas sobre el sufrimiento injusto y del mal en el mundo, esto es, las explicaciones míticas están situadas en contextos culturales e institucionales en las cuales la separación iglesiaestado no existe. La taxonomía aportada por Weber presupone la división religión-sociedad y, por tanto, entiende a esta como racionalizaciones realizadas por las religiones; pero las teodiceas pre-modernas no podían ser sino míticas, pues esta división es un fenómeno producto de la Ilustración.

Un cuarto elemento problemático de la definición weberiana de teodicea radica en la utilización de una taxonomía típico-ideal (Weber, 2014: 147) que cumple la función metodológica de levantar conceptos a la historia real. La taxonomía de racionalizaciones puras corre el peligro de introducir unas generalizaciones teóricas innecesarias, ya que la importancia de la búsqueda de sentido no radicaría en su pureza teórica. La religión, y la teodicea en particular, no son, por tanto, sistemas abstractos, sino imaginarios sociales, ideologías entendidas como modos de ser y de actuar por medio de los cuales grupos responden a la necesidad de superación del caos, de la fragmentación, y del sinsentido real que afecta y amenaza al hombre de todas las épocas.

\section{LA PREGUNTA POR EL SENTIDO DEL SUFRIMIENTO}

La apocalíptica representa, a nuestro parecer, un imaginario social que genera un tipo de literatura elaborado por diversos grupos que significó una transformación cultural de envergadura presente en todo el medio Oriente. La existencia de este imaginario explica los cambios en la manera de comprender, de valorar, y de vivir experiencias de crisis como: la pobreza, las enfermedades, catástrofes y el sufrimiento. Todas estas experiencias están enmarcadas en un nuevo imaginario, en una transformación cultural que se extendió por siglos y que se aprecia en diversos textos oficiales y marginales de este periodo.

\subsection{Teodicea deuteronomista de premios y castigos}

Un primer elemento fundamental, ya lo encontramos en textos sapienciales pre-exilicos y que volverá a aparecer en relatos apocalípticos, 
nos referimos al carácter de interrogación de la teodicea. En efecto, la pregunta por el sentido del sufrimiento es antigua y la encontramos en diversos poemas ya existentes en sumeria (Pritchard, 1969: 601). En estos dos poemas: "La Teodicea babilónica" y el segundo, "El hombre y su Dios: Una variación sumeria del motivo de Job" (Pritchard, 1969: 589) ya aparece la pregunta por el sentido del sufrimiento. En el primer poema se lee:

Mi cuerpo es. . el hambre es mi temor;

Mi éxito se ha desvanecido, mi estabilidad se ha ido.

Mi fuerza se debilita, mi prosperidad ha terminado,

Los gemidos y los problemas han oscurecido mi aspecto. (30)

El grano de mis campos está lejos de satisfacerme,

La cerveza, el sustento de la gente, está lejos de ser suficiente para mi.

¿Puede una vida de felicidad estar segura? ¡Ojalá supiera cómo!

Un segundo elemento, lo revela el hecho que la pregunta coloca en evidencia que la situación dramática y de crisis personal que vive el protagonista. En el contexto de su sufrimiento personal, la pregunta por la felicidad está en el centro de la preocupación del poeta: "¿Puede una vida feliz estar segura? ¡Ojalá supiera cómo!’. En el Segundo poema dice:

Yo, el sabio, ¿por qué estoy ligado a jóvenes ignorantes?

Yo, el que discierne, ¿por qué me cuento entre los ignorantes? ...

Lágrimas, lamentos, angustias y depresión se alojan

dentro de mí, (70).

El sufrimiento me abruma como quien hace

(nada más que) llorar,

(El demonio del destino) ... en su mano,

Lleva mi aliento de vida,

La enfermedad maligna [...] en mi cuerpo,

[...] Dios mío, tú que eres mi padre que me engendró

La oposición típica impíos/justos de los salmos muestra un contexto de confrontación entre dos grupos y que está presente en este poema: el justo es un sabio mientras que los impíos son declarados ignorantes. La descripción de la vida del justo: pobreza, gemidos, angustia, lágrimas, lamentos y depresión caracterizan a un grupo social que se contrapone a la riqueza, lucro y soberbia de otro grupo, los impíos. El Job sumerio declara que "el sufrimiento me sobrepasa como uno que no hace sino llorar...". Estos poemas reflejan la existencia de una reflexión sapiencial en el medio Oriente muy anterior a los textos bíblicos, que volveremos a 
encontrar en textos apocalípticos y sapienciales que muestran que la interrogación representa el núcleo de esta teodicea "¿Puede una vida de felicidad estar segura? ¡Ojalá supiera cómo!”, “¿por qué me cuento entre los ignorantes?". De paso señalemos que la condición de ignorancia del salmista, la falta de certezas representa una cuestión fundamental de la pregunta por el mal en el mundo. No hay teodicea sin angustia, sin silencio y por tanto sin conciencia de que no hay respuesta. Por otro lado, como lo volveremos a ver, en algunas teodiceas como esta aparece paradójicamente la invocación a Dios como Padre, etc. Nickelsburg (1993: 209212) enumera los siguientes salmos ${ }^{1}$ referidos a nuestro tema: 3, 4, 6, $9,10,13,14,15,16$, no obstante, podemos enumerar otros salmos que ponen en evidencia la pregunta por el sufrimiento En el Sal 13, 1 " ¿Hasta cuándo, Yahvéh? ¿Me olvidarás para siempre? ¿Hasta cuándo esconderás tu rostro de mí?" y en el libro de las Lamentaciones, Lam 5, 20 "¿Por qué te olvidas completamente de nosotros y nos abandonas por tan largo tiempo?". La pregunta por el sufrimiento del justo es fecundada por la experiencia profética de tal manera que la propia experiencia de sufrimiento del profeta pasa a ser parte de una nueva teodicea y se constituye en palabra de Dios. Las figuras de Oseas y Jeremías y sus confesiones, que muestran que el sufrimiento del profeta, comienzan a ser considerados como parte del ministerio, son la muestra de un cambio en la manera de considerar el sufrimiento. Autores como los ya mencionados: J. Crenshaw (1983), Charlesworth (1983), Nickelsburg (1993) sostienen que el cuarto cántico del Siervo de Yahvéh representaría una re-lectura escatológica del ministerio profético realizada en el contexto de la destrucción del Templo, ministerio marcado por el fracaso y el sufrimiento del profeta. Por tanto, no es casual que Weber afirme que Isaías, Is 52, 1353-12, Sabiduría, Sab 2, 4-5,11, es "la única teodicea realmente seria... la apoteosis del sufrimiento" (Weber, 1998c: 394) y más adelante se refiere a esta como "una glorificación del sufrimiento" (Weber, 1998c: 401).

Se puede apreciar la perspectiva deuteronomista en diversos relatos apocalípticos que emplean como argumento la desproporción entre el sufrimiento vivido y la elección divina del pueblo elegido. La promesa de la elección contrastada con el destino sufriente del pueblo en diversas catástrofes sirve de justificación para lanzar preguntas hirientes contra Dios así por ejemplo en el Testamento de Moisés, T.Moisés 9, 3 "¿Qué nación, qué país o qué pueblo de los impíos que han cometido muchas abominaciones contra el Señor, ha sufrido tantos males como nos han alcanzado a nosotros?". En otro escrito judío de la diáspora, Antigüedades bíblicas, se interroga a Dios por su actuación: "Señor Dios ¿por qué has

Abreviaturas textos bíblicos: Biblia Jerusalén (1984). 
abandonado a tu pueblo ante un enemigo triunfante? ¿Por qué has descuidado a tu heredad en los momentos de angustia?" (Ant.Bíblicas 49, 6). Y en el 4 Libro de Esdras, la pregunta por el sufrimiento del pueblo elegido es expresado colocando en duda la bondad de Dios: "¿Por qué tú destruyes a tu pueblo y eres misericordioso con tus enemigos? ¿Es que Babilonia es algo mejor que Sión?” (4Esd 3, 30) y en el Apocalipsis de Baruc: "Señor por qué has prendido fuego y asolado tu viña? ¿Por qué has hecho esto?... nos has entregado en manos de estas naciones los que se burlan diciendo: ¿dónde está vuestro Dios?” (Ap.Baruc gr 1, 1-2). En algunos textos como en el Libro de 2 Baruc y Paralipómenos de Jeremías se muestra a diferencia de otras corrientes que los sufrimientos son producto de los propios pecados "los judíos de Jerusalén fueron infieles a Yahvéh" (2 Baruc 7, 1; Paral. de Jeremías 1, 6). Dichas preguntas no parecieran ser retóricas, sino que responden a incógnitas estructurales del imaginario producto de crisis existenciales acontecidas por los respectivos grupos.

\subsection{Teodiceas predeterminacionistas}

Posterior al destierro, encontramos una mayor sensibilidad y hondura en relación con la pregunta dirigida a Dios sobre el destino de Israel. Para Sacchi (2004: 359) la pregunta por la teodicea recién surge alrededor del 160 a.C. con el Libro de los Sueños (1Enoch 83-90), sin embargo, podemos comprobar que el motivo de la teodicea está ya en el mito de los Vigilantes (1Enoch 6-11) redactado alrededor del 250 a.C.

El libro de Enoch (1 Enoch 1-39) posee diversos imaginarios que conviven en tensión unas con otras, sobre las causas del sufrimiento y del mal en el mundo, en primer lugar, presenta creencias predeterminacionistas como se aprecia en la convicción de una contaminación cósmica, y la elección desde la eternidad de los santos; en segundo lugar, por la constatación de la violencia e injusticia en el mundo, expresado como poder entregado por Dios a Shemyaza. Como se puede apreciar a pregunta de 1Enoch 9, 11 por el sufrimiento se vuelve un enigma incomprensible incluso para los ángeles ya que es Dios quien da poder a Shemyaza sobre los justos o los entrega en manos de los impíos (Job 9, 24; 16, 11; Dn 7, 25; Mc 1, 14; 9, 31; 10, 33 y 14, 41). En la oración realizada por los ángeles y Enoch, en el texto de 1Enoch 9, 11 señala:

Shemyaza a quién tú has dado poder para regir a los que están junto con él, ha enseñado conjuros... ahora pues, claman las almas de los que han muerto...tú sabes todo antes de que suceda; tú sabes estas cosas y las permites sin decirnos nada: ¿qué debemos hacer con ellos a causa de esto? 
En opinión de algunos autores como Nickelsburg y Hanson la oración de los ángeles representa a los miembros de un grupo marginal disidente que están sufriendo la opresión:

la larga oración en la cual los ángeles intercesores presenta la queja de la humanidad a Dios es más que un recurso literario por el cual el autor hace una formulación académica sobre el problema del mal. Es el amargo y desesperado grito del propio pueblo del autor, que interroga sobre el problema del mal a causa de su propia experiencia (Nickelsburg, 1977: 388389; Hanson, 1977: 219).

En este contexto, la ignorancia de los ángeles, que representa el amargo grito del pueblo, desarrolla la pregunta de la teodicea lo que representa una categoría apocalíptica central. Tanto ángeles como hombres están ante el silencio de Dios - "tú sabes estas cosas y las permites sin decimos nada". El silencio divino, en la última etapa de la historia, configura un modo de ser y de actuar de este grupo disidente del sacerdocio jerosolimitano ante el sufrimiento y el mal. Algunos autores como David Suter afirman que las creencias predeterminacionistas del sufrimiento y del mal están en relación con la cuestión de la teodicea: "el judaísmo enóquico presentó una teodicea que comprendió el mal como una aberración cósmica impuesta sobre la humanidad como una consecuencia del pecado de los vigilantes" (Suter, 2005: 332). Ciertamente es así, pero la aberración cósmica presupone la pregunta por el sentido de entregar poder a Shemyaza en 1Enoch o al Satán de Job. En ambos libros el presupuesto es el mismo: Dios entrega poder al demonio para hacer mal al grupo de los justos. Dicha respuesta tendrá en la apocalíptica una respuesta cósmico-trascendente, y en la apocalíptica posterior, se mostrará una inflexión al expresar la teodicea en términos históricos.

También encontramos un imaginario predestinacionista diseminado por diversos escritos apocalípticos. Hay que señalar que dichas teodiceas surgen en diversos contextos provocados por crisis agudas de diverso tipo: persecución, pobreza, catástrofes cósmicas, etc., las cuales llevan a la comunidad de creyentes a creer en la única posibilidad de salvación en una predeterminación divina de salvación. En textos enóquicos muestran una visión determinista de la historia en la cual la libertad del hombre queda limitada: "como ha decretado Dios, así se cumple" (1Enoch 5, 2). En otros textos (1Enoch, Jubileos, 4Esdras) se establecen diversos dualismos en los cuales es característico el carácter ético, es decir, la humanidad es dividida en buenos y malos: "los justos son pocos, los malos abundan" (4Esd 7, 51), en el Apocalipsis de Abraham (Ap. Abraham) 2324 y 1Enoch 5, 6. Los elegidos son la comunidad que, de acuerdo con el 
misterio, será salvada en la última hora ${ }^{2}$. En esta misma línea argumentativa, algunos grupos esenios y apocalípticos creyeron que los elegidos, (ellos) habían sido creados de manera predestinacionista como Adán. Así también, este imaginario concibe que los impíos proceden del primer pecado causado por los ángeles caídos como el que se expresa en el mito de los Vigilantes, y que explicaría este pecado como una mala inclinación del corazón. En cambio, otros grupos creyeron que este primer pecado se remontaría a una predestinación como se puede apreciar en Vida de Adán y Eva 20-21 con relación a la pérdida de la gloria de Adán (Sharpe, 1973: 35-46), con una demonología comparable a la que subsiste en Sab 2, 24 y otros textos ${ }^{3}$ y que volveremos a encontrar en la teodicea agustiniana. Estas teodiceas centradas en la figura de Adán muestran la desgracia de la condición humana, la perdida de la gloria divina, como producto de un primer pecado: "me has privado de la gloria de Dios", o, en el caso de 1Enoch, que piensa que el caos y sufrimiento proviene del primer pecado: el derramamiento de sangre de Abel, entendido como un misterio. Así lo expresa por ejemplo en Vida de Adán y Eva 1, 3: "dijo Adán el misterio que tú conoces, no se lo digas a Caín, este hijo (Set) te revelará a ti todo cuanto padecerás por él".

En Qumrán ${ }^{4}$ encontramos también una auto-comprensión sectaria, un imaginario predestinacionista que pretende justificar su presente y futuro, así como vemos en 4Q266 fr. 2 Col II, 18 (= CD-A I 21 - II 21) que testimonian que en Qumrán conocían el mito de los Vigilantes "los Vigilantes de los cielos cayeron" ${ }^{5}$ y que muestra la creencia que el mal es producto en el deseo de los Vigilantes: "ellos han realizado su deseo" (CD-A Col. II, 20), y no en la interioridad de los hombres o en la historia mundana como lo hará la Epistola de Enoch (1Enoch 91-105). CD-A profesa una predestinación radical entre elegidos y justos y los que pertenecen al lote del príncipe de las tinieblas. Sin embargo, otros autores sostienen una idea diferente. Por ejemplo, Diez Macho afirma que existió otra explicación al mal proveniente del rabinismo, según el cual el mal deriva de "la mala inclinación" (Gn 6, 5; 8, 21) (Diez Macho, 1984: 340) de la misma idea es J. J. Collins quien señala que en CD no está entendi-

2 Ap.Abraham 29, 13; Ap.Baruc 20, 1; 4 Esd 4, 26; 1 Enoch 80, 2; Ap 17, 14.

3 3Enoch 4, 5-8, 4Esd 7, 10ss; Ap.Abraham 23-24; Ap.Baruc gr. 4, 16.

4 Citamos los textos de Qumrán según García Martínez, F. \& Tigchelaar E. (1999). Empleamos las abreviaturas de Qumrán propuestas por la edición crítica.

5 Los lugares en que aparece menciona el mito de los Vigilantes en Qumrán son: CD-A II, Col. II, 18(4Q266) fr. 3 Col. I,18; 1QapGn ar Col.II,1; Col. IV, 16; Col.VI,13; Col.VII, 2; 4Q201 4QEnoch ar Col.I,3; Col.V,5; 4Q202 4QEnoch b ar Col.II, 3; Col. II-2- Col. III, 15; 4Q204 Col. V,3; Col. VI, 8.9-12; 4Q206 4QEnoch ar fr. 2 Col.II, 5; 4Q227 fr.2, 1 . 
do el mito de los Vigilantes como el "origen y fuente de la pecaminosidad humana" (Collins, 1997: 36) sino más bien en la inclinación (yeser) del corazón humano (1Q26, 4Q415-18, 423; Ap.Abraham 23, 13-14). En este sentido, las llamadas teodiceas de Adán presentes en escritos judíos apocalípticos y en Qumrán, y que volverán a aparecer en teodiceas judeocristianas, muestran una presencia en variados grupos judíos y cristianos (Elliot, 2002: 63; Diez Macho, 1984: 340). Las consecuencias axiológicas de estas teodiceas están a la vista, pues ellas niegan la verdad moral al margen de la revelación religiosa y por tanto la imposibilidad de cualquier progreso moral de la sociedad por la sola razón. Un segundo aspecto importante radica en inversión epistemológica similar al que describiremos con las teodiceas dualistas que veremos a continuación, según el cual, el conocimiento es dado a los creyentes y, por el contrario, los impíos caminan en la ignorancia de los decretos divinos (Mc 4, 11; 13, 35b y 14, 62-64; Rom 8, 29-30; 1 Cor 2, 7; Ef 1, 5).

\subsection{Teodicea de dualistas}

\subsubsection{Dualismo histórico}

A la teodicea predestinacionista que hemos descrito, sucede otra, que encontramos en el mismo prólogo de 1Enoch 1, 1-9, en donde se informa de un eschaton inmanente (1Enoch 5, 5-9), esto sugiere que se trata de un añadido posterior a los siguientes capítulos. En el Libro de los sueños y en el Apocalipsis de las semanas, la teodicea acontece en la historia, responsabilizando al ser humano del mal y proyectando la transformación del elegido y de la creación entera al tiempo escatológico inmanente a la historia en el cual "brillará para ellos la luz divina" (1Enoch 1, 9; 90, 38). Este interés por concentrar la teodicea en la historia se aprecia en diversos textos ${ }^{6}$ que conservan el extraño imaginario de un descenso de Yahvéh a la tierra; otra variante desarrollará el imaginario del envío de un ángel o un ser cuasi-divino como Enoch (Jub 1, 12; 4, 18. 30), o un hijo del hombre ${ }^{7}$ que tendrá su más radical desarrollo en la teodicea que habla de un Paraíso en la tierra (1 Enoch 45,5; 51,5; Ap 5,6). Por otra parte, a diferencia de la teodicea anteriormente señalada, ya no son los ángeles quienes preguntan a Dios, sino patriarcas y justos como Job, Esdras o los justos de los salmos quienes experimentan la ausencia y silencio de un Dios, lo que pareciera se vuelve contra el pueblo elegido, transformando el espasmo en escándalo e interrogación o interpelación "¡no escondas tu

Joel 3, 1-5 y Mal 4, 1; 1Enoch 1, 3-4; 4QEnGiantsb Col. II, 17

Dn 7, 9-15;4Q201 4QEnoch ar Col. I, 1-3 
rostro!" (Sal 27, 9; Hab 1, 1-2; 1QpHab Col. I, 1; 4Esd 4, 12), "no te calles" (Sal 83, 2).

En el Libro de los sueños (1Enoch 83-90) presenta esta teodicea de tipo histórica, aunque conoce el relato el mito de los Vigilantes (84, 4; 86, 1-6) según el cual toda la historia humana está contaminada desde sus comienzos por una caída primigenia de ángeles, pero que tendrá una liberación una vez finalizada el juicio de Dios. A su vez, en el libro de los Jubileos aparece este interés por la historia inscribiendo el mito de los Vigilantes en el curso de la historia de Israel, manteniendo el concurso de los demonios para explicar la existencia del sufrimiento, enfermedades y el derramamiento de sangre inocente; en el Libro de los Sueños, este giro hacia la historia se presenta de acuerdo a diferentes recursos literarios, la periodización de la historia o el recurso a figuras simbólicas como los Setenta pastores (1Enoch 89, 59-90, 42) o por reinos bestiales (Dn 7,111) o la de las setenta semanas (Dn 9,24). Al final todo será transformado como dice 1Enoch 91, 16 "el primer cielo saldrá, desaparecerá y aparecerá un nuevo cielo, y todas las potestades del cielo brillarán eternamente". En todos estos casos, la convicción es la misma: el tiempo presente es tiempo dominado por los demonios y los impíos, quienes son los responsables del sufrimiento y mal de los justos. Según el relato de 1Enoch 89, 59-90,42 el sufrimiento y el mal de las ovejas es descrito como una desobediencia de los pastores; desobediencia entendida como "exceso". Se le dice al ángel "....anota todo exceso" (1Enoch 89, 61-62; Dn 7,1-11; 8, 3.4). Con esto se señala que el mundo está bajo el poder de ángeles caídos. No obstante, el papel de la participación de los impíos o los justos y su correspondiente responsabilidad son incrementados en sucesivos escritos.

Esta reducción a la historia se aprecia en el motivo de la colaboración de ángeles y de los justos por "atar a Azazel" el cual es parte de una teodicea dualista como puede verse en 1Enoch 10, 4. 12; 21, 11; 69, 28; 88, 1 referido a la misión de ángeles Rafael y Miguel. En lo sucesivo, estas funciones serán traspasadas a patriarcas y profetas, por ejemplo, en Jubileos: "y allí será ni Satán ni ningún mal destructor" (Jub 10, 5-7; 23, 29; 50, 5). Estas funciones están vinculadas a la misión escatológica de "atar a Azazel" o "atar al fuerte" en el Testamento de los doce Patriarcas (T.XII Patriarcas) 18, 1-2, y en Qumrán (Jub 1, 20; 10, 3-6; 12, 20; 19, 28; 11Q11 Col. II 1 v. 2; 4Q21 Col.V, 5). En textos cristianos, el motivo se ve reflejado en los exorcismos de Marcos y en los otros sinópticos con relación a la misión de los apóstoles, como se aprecia en, por ejemplo, Mc 3, 15: "y tenían autoridad para expulsar demonios" También se puede apreciar en Ef 6, 12: "nuestra lucha no es contra sangre ni carne, sino contra principados, contra autoridades, contra los gobernantes de estas 
tinieblas, contra espíritus de maldad en los lugares celestiales"8. Esta comunión o colaboración en la lucha contra el mal también se aprecia en la descripción, y permanente referencia a Caín y la sangre derramada de Abel, como pecado originario (Jub 4, 18-19; Sefer Hekhalot 4, 2.5); también en el Testamento de Abraham (T.Abraham III, 4; VII, 3-17), a Caín como "hijo de la serpiente" (Pseudo Jonathan a Gn 5, 3; Evangelio de Felipe 49) así como también en las listas de "hijos de Belial" o "hijos de la ira" que representan creencias predeterminacionistas acerca de grupos de elegidos y de condenados que continúan diacrónicamente el pecado de los ángeles caídos. En Qumrán encontramos la siguiente estructura sincrónica: hombres-espíritus-Belial, como puede verse sobre todo en 1QM Col. I, 15: "Belial, y todos los ángeles de su dominio y todos los hombres de su lote"; en términos fragmentarios y generales: "todos los hombres del lote de Belial" 4Q256 Col. II, 12"; sujetos particulares: Jannes y sus hermanos, los necromantes, adivinos (4Q271; 4Q267frag. 2; 4Q379 frag. 22, 9) o indeterminados personajes históricos: "maldito sea el hombre de Belial" (4Q386).

Esta colaboración de atar a Azazel también se aprecia, en otros términos, en la oración e intercesión de profetas y patriarcas. Así, a diferencia del mito de los Vigilantes en el cual son los ángeles quienes interceden y preguntan, en el Libro de los Sueños (1Enoch 83-90) es Enoch, quien intercede por los justos (83, 10; 84, 1-6). La oración de Enoch es para que Dios deje un "resto sobre la tierra y no la aniquile toda" $(83,8)$; "a los justos y rectos mantenlos". El clamor del pueblo (1Enoch 8, 4; 9, 3. 10-11) de Enoch y los ángeles guarda relación con el tema de la teodicea (Davidson, 1992: 56). En el libro de los Jubileos, la oración de los patriarcas posee un carácter exorcista de bendiciones y oraciones que la sitúa en las coordenadas de la lucha contra el mal. Noé (Jub 10, 1-3-7); las oraciones de Abram (Jub 10, 16-23); Moisés (Jub 1, 20) responden a este modelo. M. Davidson lo explica claramente:

...la preocupación de explicar por qué la aflicción de Israel era tan grande, mucho más de lo que parecía merecer; por qué Israel ha sufrido gravemente y hasta cierto punto más allá de la medida de su pecado (Davidson, 1992: 107).

Davidson no percibe la función de la interrogación en la oración de patriarcas y profetas. La oración no es, en este contexto, un acto piadoso ni litúrgico, sino que comienza a comprenderse como una praxis vicaria a

Véase 1Enoch 10, 4; 69,28; Jub10, 5-7; 23, 29; 50, 5; TestLevi 18,1 y Mc 3, 22. 
los sacrificios, la cual posee una función escatológica de los profetas y patriarcas para exorcizar el sufrimiento y el mal en el mundo.

La reducción a la historia de este tipo de teodicea se puede apreciar en la Epistola de Enoch donde se subraya el carácter histórico del pecado, como, por ejemplo, en 1Enoch 98, 4: "tampoco el pecado fue enviado a la tierra, sino que los hombres lo crearon de sí y gran maldición tendrán los que lo hicieron". Lo cual se asemeja al pensamiento del Sirácida (Si 21, 27): "cuando el impío maldice a Satán él se está maldiciendo a sí mismo". Aunque conoce el mito de los Vigilantes $(91,13)$, no se refiere a éste para explicar la injusticia en el mundo. Esta reducción a la historia también es desarrollada a través de un dualismo epistemológico estableciendo un modelo crítico de dos fases historia-eschaton. El sufrimiento e injusticia presente en la historia, paradójicamente, se revela a los elegidos en el presente, a los cuales se les promete que serán transformados en ángeles (1Enoch 51, 4) ${ }^{9}$ (Himmelfarb, 1993: 40). Esta lucha entre los hijos de la luz y de las tinieblas representa una crisis cultural que se expresa como un dualismo epistemológico, en la cual la revelación es dada en el presente a los elegidos y negada a los impíos, como en 1Enoch 1, 2; 9, 11: "hubo un hombre cuyos ojos fueron abiertos por Dios... visiones que no son para esta generación, sino para una lejana que ha de venir". La ignorancia refleja la crisis acerca del sentido de la historia no revelada para el presente a todos sino a los elegidos (ver 1QpHa Col. VII, 1; 1Enoch 82, 2; Ap. Bar 51, 7). En un texto de Qumrán, 1Q27 (1QMyst), se señala que los impíos "no conocen el misterio futuro, no comprenden las cosas antiguas. Y no saben qué les va a suceder; y no salvarán sus almas del misterio futuro". Desde un punto sociológico, es importante apreciar cómo este dualismo epistemológico caracteriza las teodiceas dualistas proporcionando razones y sentido a grupos de grupos que sufren pobreza, adversidad y persecución, prometiendo a estos una vida gloriosa postmortem (1Enoch 103, 4). Y, por el contrario, el dualismo epistemológico refleja una crítica contra los poderosos y ricos (1Enoch 94, 8; 95, 8). Este crítica social que enfrenta a poderosos/pobres (los sabios y justos) se ve reflejada en diversos textos en donde señala que los hombres escuchan bien todo, pero ellos no saben lo que significa; los sabios en cambio comprenden las señales de Dios (Dn 12, 10 y 1QS Col. IX, 17-19); en 4Esd 5, 7 señala; "la muchedumbre no nota, que el tiempo final está irrumpiendo" (ver Ap.Bar 27, 15) y los que "lo saben no lo dicen" (Ap. Bar 48, 32s); y en textos cristianos que conservan esta teodicea como 1

9 491c; 4Q496; 4Q548 4QVisions of Amramf ar.; 1QM Col. I, 8; Col. XVII, 5-7; 1QS Col. IV, 7; 4Q496. fr. 3. Col. I, 79; 1En 104 y AscMoises 9-10; Actas de Pablo II, 5. 
Co 2, 7-10: “... la sabiduría oculta que Dios predestinó antes de los siglos para nuestra gloria, 8 la cual ninguno de los poderosos de este mundo conoció, porque si la hubieran conocido, nunca habrían crucificado al Señor de la gloria" y en la fuente de los dichos Lc 10, 21//Mt 11, 25: "...Yo te alabo, Padre, Señor del cielo y de la tierra, porque escondiste estas cosas de los sabios y entendidos y las has revelado a los niños".

\subsubsection{Dualismo temporal en Qumrán}

En opinión de Charlesworth la cuestión de la teodicea en Qumrán tuvo una respuesta positiva: "los intentos de resolver el problema de la teodicea no molestaron a los qumranitas. No hubo sufrimiento absurdo contemplado en los documentos de Qumrán" (2003: 482). La secta caracterizada por miembros (sacerdotes, escribas) que conocen la Escritura celebra su exilio en el desierto al interpretar el texto de Is 40, 3 (1QS 8-9) en el contexto de un dualismo temporal. El tiempo presente es un tiempo de preparación "la opción fundamental en la búsqueda por una respuesta a la teodicea es el cumplimiento proléptico" (2003: 479). No obstante, en algunos textos se puede percibir una transformación escatológica del dolor en vista de la glorificación post-mortem de los miembros de la secta como puede verse en 4Q491c; 1QHa Col X, 10-12; 32-33; Col. XIII, 20-39; 4Q431 fr.1. Todo esto implica que la pregunta y el desgarro por el sufrimiento actual estuvo presente; múltiples textos de Qumrán muestran que la angustia por el pecado de la nación constituye uno de los ejes estructurales del imaginario qumranita. No sin razón, Paolo Sacchi ha señalado que "el hombre mismo, en la concepción del esenismo no es más que pecado" (2004: 362); el texto de 1QH 4, 29: "el hombre está en pecado (awon) desde el seno materno y en iniquidad culpable hasta la vejez" es claro al respecto. La comunidad registra en los pesharim la experiencia del silencio y la pregunta por el ocultamiento del rostro de Yahvéh en los últimos días es un tema reiterado, por ejemplo, en Catena 4Q177 Col. II, 8: amargamente el profeta afirma que "se olvidó de mi Yahvéh". En opinión de J. D. Crossan, la destreza metodológica muestra un contexto de clases subalternas "que tendría la posibilidad de apreciar la exactitud erudita de las citas exegéticas (1994, 427). Esta actitud de purgación del tiempo presente se aprecia en textos apocalípticos tardíos contextualizados en la destrucción del Templo de Jerusalén el año 70 d.C. como 4Esdras. En este texto, se afirma: "¿Por qué tú destruyes a tu pueblo y eres misericordioso con tus enemigos? ¿Es que Babilonia es algo mejor que Sión?" (4Esd 3, 30). Y en Ap.Baruc se expresa: "Señor porque has prendido fuego y asolado tu viña? ¿Por qué has hecho esto? $[\ldots]$ nos has entregado en manos de estas naciones los que se burlan 
diciendo: ¿dónde está vuestro Dios?” (Ap. Baruc 1, 1-2). Estas imágenes colocan en evidencia que la teodicea en Qumrán y en textos apocalípticos posteriores se constituye como tal en medio de una crisis experimentada como ausencia, silencio que provoca la interrogación por el escándalo al constatar la desproporción entre sufrimiento de los justos y el progreso de los miembros impíos de la propia nación o de las naciones circundantes.

\subsubsection{Dualismo espacial}

Dentro de las teodiceas dualistas presentes en la apocalíptica encontramos la idea del mundo "de arriba" como realidad paralela al mundo "de abajo", caduco. Estas teodiceas son importantes porque guardan relación con el desarrollo de la mística en Occidente. En estas teodiceas, la idea que los justos ya están en el paraíso o en el seno de Abraham y que no tienen que esperar a una solución escatológica futura aparece bien documentadas. Por tanto, estas teodiceas reflejan una escatología realizada según la cual ahora los justos están en el paraíso. Habría que asociar con este tipo de teodiceas, el motivo del viaje y del ascenso-descenso que encontramos en la apocalíptica judeo-cristiana como en 1Enoch 12, 1 que dice: "Antes de estos sucesos, Enoch estaba oculto (elemfhte) y ninguno de los hijos de los hombres, sabia dónde se escondía, dónde estaba, ni qué era de él" ${ }^{\prime 0}$. En este mismo sentido, en el Libro de las Parábolas J. VanderKam y John Collins proponen que 1Enoch 70-71 representa un esquema literario en el cual el Hijo del hombre es el doble sobrenatural de Enoch, la contraparte angelomórfica de Enoch (Vanderkam, 2010: 183-184). En estos escritos, según estos autores, Enoch llega a ser, se transforma, en su doble sobrenatural preexistente (Vanderkam, 2010: 183-184; Collins, 2010: 270). La entronización del Hijo del hombre es un tema distinto de la resurrección post-mortem, aquella implica la transformación de la creación, de los justos que se transformarán en ángeles en el cielo, y los justos que morarán sobre la tierra (1Enoch 51,1-5). R. Elior (2004: 29) señala que este modelo del doble sobrenatural también se repite en el caso de la literatura de los Hekhalot, en la cual Enoch es la contraparte de Metatrón, y también el caso de Rabbi Akiva y Rabbi Ishmael, que son la contraparte mística de Moisés y Aarón (2004: 33). En general, los diversos ejemplos muestran que al prototipo divino le corresponde un arquetipo terreno. El mundo terrestre es visualizado de acuerdo con su doble celeste: hombres, templo, oficios, etc. poseen su arquetipo divino

10 La cursiva es mía. Para otros textos, véase: 1 Enoch 21,$1 ; 22,1 ; 24,1 ; 26,1 ; 28,1$; 29,$1 ; 33,1 ; 34,1 ; 35,1 ; 36,1$ 
en el cual ocurre una simultaneidad/causalidad entre cielo y tierra (2004: 59). Así entonces, no es casual que héroes como Enoch, Elías, Isaías, los patriarcas son enviados a socorrer al pueblo de Dios (Mc, 1, 2 y 9, 11) o son arquetipos de los justos como Enoch o José (Sab 2, 18; 5, 5); y en Apocalipsis de Sofonías (Ap.Sof.) 9, 4 siguiendo el modelo de Moisés: "todos los justos, vale decir Abraham, Isaac, Jacob, Enoch, Elías y David y hablan con él como un amigo habla con un amigo". Estas teodiceas conservan la idea de que los arquetipos divinos, están en el paraíso; los personajes terrestres como los mencionados poseen un alter-ego celeste, a esto se debe la creencia en una creación angelomórfica del hombre en el inicio del tiempo, en la cual los justos que han muerto permanecen en el paraíso.

\subsection{Teodicea del Deus absconditus}

Vinculado a la figura de Adán y su relación con el mal encontramos diversos relatos como 3Enoch 4, 5-8, que desarrolla un tipo de teodicea particular debido al recurso epistemológico de la insondable sabiduría divina, que también aparece en la tradición islámica. Este recurso del Deus absconditus expresa una vertiente sapiencial no exclusiva de la apocalíptica judía acerca de la teodicea caracterizados por el recurso a múltiples preguntas realizadas por Dios al justo, relativas a los misterios del cosmos, como podemos ver en el libro de Job y que repetirán otras narrativas apocalípticas como 4Esd $(1,6.7 ; 3,28.31 .35)$ y Ap. Baruc $(2,4 ; 4,5$. 7. 8), así como en Jb 38, 4; 38, 12-13; 42, 1-4:

¿Dónde estabas tú cuando yo fundaba la tierra? [...] ¿Has dado órdenes a la mañana alguna vez en tu vida? ¿Le has mostrado al alba su lugar, para que ocupe los confines de la tierra y sean sacudidos de ella los malvados? [...] Yo reconozco que todo lo puedes y que no hay pensamiento que te sea oculto. "¿Quién es el que, falto de entendimiento, oscurece el consejo?" [...] así hablaba yo y nada entendía, eran cosas demasiado maravillosas para mí, que yo no comprendía.

El libro de Job no es una renuncia a la pregunta de la teodicea (Weber, 2014: 617) sino que, en primer lugar, coloca en evidencia la insuficiente de la teodicea deuteronomista de premios y castigos; y, en segundo lugar, pone en evidencia que la imposibilidad del conocimiento de los misterios divinos se transforma en el fundamento del carácter práxico de la actuación humana sobre el sufrimiento, renunciando así, a una especulación. Este carácter conflictivo responde a la lucha contra otras teodiceas entendida como respuesta teorética por Elifaz. En ese sentido 
J. Crenshaw (1983: 79) subraya que la teodicea es una pérdida de dignidad sustancial perdida de dignidad humana" (Crenshaw, 1983: 79) habría que decir que el recurso a la teodicea del Deus absconditus representa un intento por salvaguardar la trascendencia divina llamando al hombre a la práctica. Sin embargo, como ya hemos señalado existe a juicio de Crenshaw, Putt y Eichrodt un movimiento contrario, es decir, la negación de toda racionalización del sufrimiento humano, como ocurre en algunos textos: "¿Para qué salí del vientre? ¿Para ver trabajo y dolor, y que mis días se gastaran en afrenta" (Jer 20,18) o, el grito de Jesús en la cruz del Golgota "Eloi, Eloi!, ¿lama sabactani? (que significa: Dios mío, Dios mío, ¿por qué me has desamparado?)?” (Mc 15, 34; 4Ezra 4, 23).

\subsection{Teodicea de entrega}

En opinión de Anti-Laato (2003: xlviii) encontramos una teodicea de comunión en el libro de los Salmos, el libro de Job y la literatura profética. La idea central de esta teodicea no es que el sufrimiento pueda llevar al profeta o visionario a una mayor cercanía con Dios, sino que el ministerio profético es considerado un tipo de función escatológica. Erróneamente, R. Horsley sostiene que: "no hay referencia a un especial tiempo de tribulación o sufrimiento en ninguno de los textos apocalípticos del segundo templo" (2012: 45). Uno de los motivos más relevantes de la expresión los "últimos días" son los dolores escatológicos ${ }^{11}$ como un tiempo cualitativo del sufrimiento y de la calamidad que caracteriza al presente comentado a menudo en textos de Qumrán ${ }^{12}$. Esta escatologización del sufrimiento presente caracteriza el tiempo como un "tiempo de la impiedad", "tiempo de la aflicción", "periodo de la ira" (4QpHos fr. 1 Col. I, 12), días de purificación y prueba (4Qcatena Exegética [4Q177] Col. II, 9-10; IV, 13), un tiempo cualitativamente distinto, en 1QM Col. II, 2: "será un tiempo de sufrimiento, para todo el pueblo redimido por Dios. De todos sus sufrimientos ninguno será como éste", motivo que se repite en Mc 13, 19 que comenta el motivo de dolores escatológicos: “...habrá una tribulación como no la hubo desde el principio de la creación”. La caracterización del tiempo final como un tiempo de sufrimiento explica que la reflexión post-exílica relaciona los sufrimientos del profeta y justos como un ministerio escatológico como Jeremías, el profeta del Deutero Isaías 52, 13-53-12 y Sab 2, 4-5, 11; 1QHa Col X,

11 Ver Dn 12, 1; Zac 9-14; 13,1-7; 4Esd 5,1-12; 6, 13-28; 9, 1-6, Mc 13, 19; 14,27.

12 Ver 1QpHab Col. V, 8; CD Col. V, 20; VI, 10.14; Col. VII, 11-21; Catena Exegética Col. IV, fr. 19, 13; 1QM Col. XV, 1;4Q496 Col I, frag. 2, 3; 4QPsalms Pesher Col. II, 10; Col. III, 3; 4Q267 frag.9 Col. V,1; 4Q284 frag.4,6; 4Q491,18; 4Q510 frag.1,6-8. 
10-12; 32-33). En este último texto, menciona las confesiones de Jeremías, en un contexto escatológico, se lee:

tú me has puesto como un reproche y burla de los traidores...he llegado a ser el objetivo de calumnias de los labios de los hombres violentos, motivo de burla de sus dientes y he llegado a ser el hazmerreír de los impíos y la asamblea de los malvados está levantada contra mí (Col. X, 10-12;32-33)

Y más adelante en Col. XIII, 20-39 representa una larga letanía de dolores "agonía y penas me rodean", "planean intrigas" (4Q431 fr.1), etc. De la misma manera que Jesús posteriormente, el Maestro de Justicia cita los salmos 22, 2; 42, 6 y 69 (ver 1QHa 20, 23-24) asumiendo ideas semejantes con relación a los dolores del mesías. Tradiciones cristianas, específicamente en el relato de la pasión pre-marcano, asumieron este diseño radicalizando escatológicamente dicha teodicea ${ }^{13}$, entendido que el sujeto que sufre no es sólo un profeta sino el hijo de Dios. Esto es, un paso por integrar el sufrimiento no sólo como característica intrínseca a la condición humana sino también de Dios. Las innumerables citas de los Salmos esparcidas por estos capítulos, así como las referencias al justo (ver 1Enoch 38, 2; 53, 6; 71, 16) pero también Is 53, 11 y Sab 2, 12-20; 5, 1-7, muestran una radicalización del motivo mítico del justo sufriente las cuales están concentradas en las profecías de la pasión Mc 8, 31; 9, 11-13 y 10, 33 y en capítulo 15 del evangelio. En este cuadro, el sufrimiento escatológico es comprendido, no como un castigo o pedagogía divina, el dolor del profeta no es un momento externo o accidental a su persona y su misión, sino que es asumido como la propia historia de sufrimiento de la condición humana y, por lo tanto, el profeta participa de una función escatológica mediante la cual éste colabora en la consumación del plan de Dios en la historia. Esta teodicea de comunión elaborada por escribas, cristianos galileos y urbanos, -y no por una "tradición sumamente culta y refinada" como pretende Crossan (1994: 433), medita, transmite y construye mediante el esquema de humillación-exaltación ya existente una respuesta al problema del sufrimiento del justo. Esta teodicea es un imaginario radical que enfrenta el problema del sufrimiento, perspectiva ausente tanto de la tradición deuteronomista como en la tradición de la pasión del justo presente en el salterio. Por otro lado, en este grupo debemos enumerar las teodiceas que hablan de la entrega del justo a manos de Dios. Dichas teodiceas están fundadas en la creencia de la "autoridad"

13 Ver Sal 54, 5; 37, 32; 63, 10; 71, 10; 86, 14; 109, 16); el motivo de los testigos falsos (ver Sal 27, 12; 35, 11), así como el del silencio del justo frente a la acusación de los adversarios (Sal 28, 14-16; 39, 10) 
que Dios transfiere a los enemigos. Existen textos veterotestamentarios y apócrifos que hablan de esta "autoridad" dada por Dios a Shemiaza o a los enemigos del pueblo elegido o de los justos (1Enoch 9, 7; Testamento de Job 20, 3), en el texto de Job 1, 1-11; 9, 24 y 16, 11 se dice: "Dios me ha entregado al mentiroso, en las manos de los impíos me ha hecho caer". Esta tradición la encontramos también en textos apocalípticos como el ya mencionado de 1Enoch 9, 7: "Semyaza, a quien tú has dado poder para dominar...; tú sabes estas cosas y tu permites esto sin decirnos nada. En otro texto apocalíptico Dn 7, 25 se afirma: “[...] y los santos serán entregados en sus manos hasta tiempo, tiempo y mitad de tiempo"; en el Ap.Abraham XXIII, Abraham interroga a Dios por haber dado tanto poder a Azazel: "O Eterno, poderoso! ¿Porque tú has dado tal poder para destruir a la generación de hombre en sus trabajos sobre la tierra?". Estos textos son antecedentes fundamentales que no tienen como función explicar el sufrimiento sino, por el contrario, interrogan a Dios por el sufrimiento vivido y que son asumidas de una manera radical en el evangelio de Marcos.

También debemos mencionar en este punto diversos textos tardíos que muestran la creencia en el sufrimiento de Dios o de los ángeles. Algunos textos que debemos mencionar son Mc 14, 32-44; Lc 22, 43-44: “...apareció un ángel del cielo para fortalecerle. Y angustiado, oraba con mayor intensidad, de modo que su sudor era como grandes gotas de sangre que caían hasta la tierra". Es posible que, estemos en presencia de una radicalización del motivo del justo que sufre, comprendido por comunidades cristianas como el Hijo de Dios, es decir, las primeras comunidades cristianas comprendieron que la cuestión del sufrimiento alcanza al mismo Dios. Un giro fundamental radica en que el sujeto que interroga por el sufrimiento es el Hijo, el propio de Dios, de tal manera que éste queda integrado dentro del sufrimiento. Este aspecto lo encontramos en textos contemporáneos en los cuales el sufrimiento de los justos y en el llanto de los ángeles, Ant. Bíblicas 19,16 “...su aspecto se transformó en gloria, y murió en gloria según la palabra del Señor, que lo enterró según lo había prometido. Los ángeles lloraron su muerte y lo precedieron fuegos [...] en aquel día a causa de la partida de Moisés". La pregunta por el sufrimiento no se responde, pero la creencia que los ángeles lloran muestra una comprensión del sufrimiento interno de Dios en unión con el sufrimiento humano; así también en el Testamento de Abraham B 3, 10 : encontramos el tema del sufrimiento de Dios a través de las lágrimas de Miguel arcángel "Miguel al verlos llorando, se puso a llorar con ellos". La versión A añade "y las lágrimas del príncipe al caer sobre la palangana, se convirtieron en piedras preciosas". La imagen del poder de Dios sucumbe en estos textos ante otra que, muestra la debilidad de Dios "es más 
fuerte que los hombres" (1 Cor 1, 25), esto es, el sufrimiento de Dios, de los ángeles, y de los hombres, posee una estructura paradójica: el sufrimiento de Dios o del Hijo de Dios (ángeles) se transforma en lo más valioso que tienen los hombres. Los relatos de la comunidad marcana (Mc 14, 32-44) y de la comunidad de Lucas (Lc 22, 43-44) asumen motivos míticos en los cuales se habla de lágrimas de divinidades que producen bienes diversos... en nuestro caso, las lágrimas vertidas por los ángeles debido al sufrimiento de Israel se transforman en perlas (1 Cor 1, 25; T.Abraham. A 5, 10-14).

\section{APORTES A UNA SOCIODICEA}

En términos esquemáticos podemos decir que la investigación ha mostrado los siguientes insumos para una sociología del sufrimiento. Primero, la pregunta que las víctimas hacen por el sentido del caos como elemento esencial de la respuesta; segundo, esta pregunta acontece en un contexto histórico social y no ritual; tercero, es una acción social literaria y terapéutica que pretende la superación de mal; cuarto, se trata de una auto-convocatoria de un proyecto histórico-social.

\subsection{La pregunta por el sentido del sufrimiento}

Entender la teodicea como racionalización que clausura el problema del sufrimiento se contradice con los textos estudiados en donde la pregunta del visionario en relatos míticos es la pregunta de un grupo social y, por tanto, no es algo exógeno a la misma respuesta que ella da. La religión y la teodicea no son, en consecuencia, sistemas abstractos, sino modos de ser y de actuar por medio de los cuales los pueblos responden a la necesidad de superación del caos, de la fragmentación, y del sin sentido real que afecta y amenaza al hombre de todas las épocas. La pregunta del visionario no es un recurso retórico, sino que refleja la condición ante el silencio de Dios de aquella comunidad ante el sufrimiento injusto. La pregunta del creyente ante el sufrimiento muestra la fractura entre experiencia y lenguaje presente en diversos autores (Frank, 2001: 355; Ortega, 2008: 37). Tanto en el caso de las teodiceas de predestinación como las que emplean el recurso a la inconmensurable sabiduría divina muestran una reducción al silencio, al abandono de Dios, experiencia que se transforma en pregunta sorda lanzada contra Dios, queja, protesta que carece de un lenguaje inexpresable (Frank, 2001: 355).

Ambos aspectos, pregunta y respuesta, representan la condición humana considerada histórica y contextualmente situada. La pregunta de la teodicea es la crítica a las anteriores justificaciones que legitiman el su- 
frimiento y el mal y por lo mismo, la pregunta muestra, en primer lugar, el escándalo de profetas y justos, pregunta que interroga al mismo Dios que lleva al creyente más allá a la superación de teodiceas previas que clausuran las preguntas acerca de las ultimidades.

\subsection{Carácter existencial de la teodicea}

Mucho se ha escrito sobre el contexto en que emergen los escritos apocalípticos. Collins habla de situaciones "percibidas como crisis", para explicar que algunos textos no poseen un contexto de persecución o crisis; hemos mencionado las opiniones de Putt (1997), E. Boase (2008) y J. Crenshaw (1983), que hablan de una teodicea de protesta la cual refleja una dinámica que muestra un conflicto entre visiones conservadoras sobre el sufrimiento y otras que muestran un Dios que participa del sufrimiento del profeta. Pareciera correcta hablar de una existencia de teodiceas de protesta (Putt, 1997: 463; Bowker, 1970: 10). En diversos casos encontramos que la reflexión apocalíptica no pretende sólo un fin esotérico, sino que pretende impugnar, contradecir, una opinión común sobre la catástrofe o la crisis sociales vividas, así como la crisis del destierro (Boase, 2008: 450). El fracaso del proyecto de restauración y fragmentación del judaísmo post-exílico, la creciente helenización del territorio y de la cultura judía pudieron desencadenar más de alguna reflexión en torno a una situación de crisis social. Por otro lado, un modo de comprender esto se plantea en el contexto de los textos como Daniel, las Parábolas y la Epístola de Enoch, los cuales manifiestan, como contexto próximo, la crisis que significó la persecución de Antioco Epífanes. De la misma manera, textos como Apocalipsis de Juan, 4Esdras, Apocalipsis de Abraham tienen como contexto próximo la crisis que significó la destrucción del templo de Jerusalén en el año 70 d.C. No obstante, en otros textos se muestra el empleo de diversos modelos heurísticos para comprender el problema del sufrimiento. Por ejemplo, la creencia apocalíptica de un incremento del mal en la última etapa de la historia es concomitante con la creencia de que la experiencia actual es de sufrimiento y persecución, los cuales son una preparación de la venida de Dios. Las señales de los últimos tiempos, por lo tanto, son comprendidas dentro de una lógica en la cual el tiempo presente es malo. En otros casos, el recurso a la experiencia religiosa del destierro, usado en diversos textos, evoluciona mostrando diversas reflexiones sobre la situación de crisis vivida en el presente. En algunos de estos textos la crisis existencial por la cual atraviesa la comunidad parece evidente, en otros menos. En algunos casos, como el Mito de los Vigilantes, Jubileos, Job, el contexto próximo no resulta tan evidente. Con todo, autores como Suter (2005: 331) sostienen 
que el contexto de mito de los Vigilantes pretende expresar una contaminación del sacerdocio jerosolimitano. Como sea el caso, en 1Enoch asistimos a un modelo distinto de enfrentar el origen del sufrimiento y del mal que permanecerá en múltiples escritos. Esto significa, a nuestro parecer, que se constata que hubo diversas maneras de enfrentar las interrogantes de la crisis. En algunos casos, consideramos que la respuesta fue desarrollada con un carácter profético-visionario, en otras como una cuestión esotérico-sapiencial.

\subsection{La teodicea como acción social que exorciza el mal social}

Como ha sido puesto en evidencia por M. Sarot, la teodicea entendida como pensamiento lógico, sería "un fenómeno típicamente moderno" (Sarot, 2003: 21) que marcaría: "el surgimiento de un nuevo modo de pensar sobre el mal" añadiendo: "sería equivocado usar el término teodicea para aproximaciones bíblicas u otras aproximaciones pre-modernas al mal..." (Sarot, 2003: 5). El concepto de teodicea usado por Weber y de sucesivos autores, está planteado como racionalizaciones en función del teísmo que establece la incompatibilidad entre la existencia de un Dios bueno, poderoso, sabio y las imperfecciones del mundo histórico (Basinger, 1994: 89). En la antigüedad, por el contrario, encontramos que la teodicea tiene que ver más bien con una terapéutica y una acción social que exorciza la presencia del mal en el mundo mediante relatos, ceremonias, conjuros, y otras técnicas. Como lo apreciamos en nuestra exposición, las explicaciones del mal en periodos pre-modernos son expresadas a través de narrativas míticas ficcionales, mediante ritos y relatos míticos, no mediante racionalizaciones lógicas. Acertadamente Lluis Duch ha sostenido que "el mito ha realizado -y realiza-, una saludable función teodiceica" (Duch, 2002: 34). En este sentido, sería más acertado decir que en la antigüedad existen, propiamente hablando, sociodiceas, no teodiceas. La pregunta por el sentido del sufrimiento social acontece en un contexto cultural, histórico-social; en cambio el concepto weberiano de teodicea camina sobre el presupuesto de la separación entre religión y sociedad cuestión que en la antigüedad no acontece, más aún, son las instituciones sociales, no las iglesias, las que formulan la preguntas sobre el sentido del sufrimiento injusto y del mal en el mundo. Las cuestionadas explicaciones míticas están situadas en contextos culturales e institucionales, no eclesiales, y si bien existen ritualizaciones, y técnicas de exorcizar el mal, dichas prácticas están en relación con la necesidad de liberar al hombre socialmente situado ante la presencia del caos.

\subsection{Las teodiceas como auto-convocatoria}


Las teodiceas estudiadas muestran que ellas se constituyen como auto-convocatorias históricas en la cual determinados se reconocen como "los elegidos", "los pobres", "los santos". Esta auto-convocatoria se expresa por una reducción a la historia de la libertad humana (1Enoch 98, 4). Esta reducción a la historia también es comprendida dentro de una visión dualista arriba/abajo e historia/eschaton. En ambos modelos el concepto de ignorancia escatológica establece un modelo crítico de dos fases historia-eschaton, de tal manera que el sufrimiento e injusticia presente en la historia se justifica y revela a los elegidos en el presente ayudando a estos a perseverar en sus sufrimientos y gracias a los cuales serán transformados en ángeles (1Enoch 51, 4) (Himmelfarb, 1993: 40) ${ }^{14}$. Esta convocatoria también se aprecia en el tema de la lucha espiritual entre los hijos de la luz y de las tinieblas, la cual representa una crisis cultural y política que se expresa en un dualismo epistemológico típico de grupos militantes minoritarios, según la cual la revelación del curso de la historia está dada en el presente a los elegidos y negada a los impíos (1Enoch 1, 2; 9,11; 1QpHa Col. VII, 1; 1Enoch 82,2; syBar 51,7). Desde un punto de una sociología del sufrimiento es importante atender al papel referencial de este dualismo epistemológico que caracteriza las teodiceas dualistas proporcionando razones y sentido para enfrentar la adversidad, la persecución y compromiso de estos grupos disidentes. En este mismo sentido la ignorancia representa una crítica contra la racionalidad mundana: "sólo los sabios comprenden las señales de los tiempos" (Dn 12, 10). Los hombres escuchan bien todo, pero ellos no saben lo que significa; los sabios en cambio comprenden los signos de los tiempos como lo vemos en Dn 12, 10 y 1QS Col. IX, 17-19; 4Esd 5, 7. Es un error, por tanto, creer que las teodiceas dualistas son una huida de los dolores del presente; por el contrario, en determinados casos, esta epistemología representa una crítica aguda a los poderosos del mundo.

\section{PALABRAS FinALES}

La presentación realizada coloca en evidencia varios aspectos a considerar. Primero la teodicea está en relación con la pregunta por el senti-

14 Ver 491c ;4Q496; 4Q548 4QVisions of Amramf ar ; 1QM Col. I, 8; Col. XVII, 57; 1QS Col. IV, 7; 4Q496. fr. 3. Col. I, 79; 1En 104 y AscMoises 9-10; Actas de Pablo II, 5 . 
do del sufrimiento, el cual posee un carácter ficcional y práctico. No encontramos una racionalización que clausura las preguntas últimas, sino, más bien, la lucha histórica contra el sufrimiento experimentado e incluso contra una mala teodicea que justifica el sufrimiento y se enquista como parte de la injusticia en el mundo. Como lo afirma Russell, uno de los temas principales de la apocalíptica judeo-cristiana será la pregunta por el sentido del sufrimiento y la manera de enfrentar el sufrimiento y la injusticia (Russell, 1964: 237), ciertamente, no el único, pero dicho interés se aprecia en no pocos escritos. En segundo lugar, la necesidad de comprender las preguntas de las víctimas y su concomitante crisis en vista de superar las actuales emergencias del mal. Las experiencias del sufrimiento son variadas y no se pueden reducir a las grandes catástrofes nacionales sino a situaciones personales o crisis culturales que se prolongan en el tiempo, captadas como tales por creyentes y que buscan dar una respuesta. Además, el estudio ha presentado múltiples textos que hablan una teodicea de protesta comprendida, en primer lugar, como una protesta e interpelación del vidente o profeta a la situación de sufrimiento, explotación o catástrofe que vive el pueblo; en segundo lugar, dicha protesta se resuelve de acuerdo con el presupuesto de una ignorancia y enigma que siempre presenta el caos en otros por el recurso a la insondable sabiduría de Dios. A juzgar por el análisis, ambos elementos resultan inevitables, las situaciones de injusticia y catástrofes que acompañan al ser humano colocan a éste ante el abismo y el caos siempre de manera provisoria, y por tanto, la búsqueda de un significado a estas interrogantes no debiese evaluarse ligeramente desde fuera de las situaciones históricas, más bien, creemos que el estudio del sufrimiento social de ayer y de hoy se hace más necesario y sigue siendo la tarea pendiente para la antropodicea moderna.

\section{REFERENCIAS}

Basinger, D. \& Basinger, R. (1994). The Problem with the 'Problem of Evil'. Religious Studies, 30(1), 89-97.

Berger, P. (1967). The Sacred Canopy. Elements of a sociological theory of religion. New York: Anchor Publisher.

Boase, E. (2008). Constructing Meaning in the Face of Suffering: Theodicy in Lamentations. Vetus Testamentum, 58(4/5), 449-468.

Bowker, J. (2006). Diccionario abreviado Oxford de las religiones del mundo. México. Paidós.

Charlesworth, J. H. (2003). Theodicy in Early Jewish Writings. En A. Laato and J. Moor (Eds.), Theodicy in the world of the Bible (pp. 470-508). Leiden-Boston: Brill. 
Collins, J. (2010). A imaginação apocalíptica. Uma introdução à literatura apocalíptica judaica. São Paolo: Paulus.

Collins, J.J. (1997). Apocalypticism in the Dead Sea Scrolls. London \& New York: Continuum Publishing Company.

Conradi, C. (2016). Modernity and Evil: Kurt H. Wolffs Sociology and the Diagnosis of Our Time. Human Studies, (39), 465-480.

Crenshaw, J., (ed.) (1983). Theodicy in the Old Testament. Philadelphia, London: SPCK.

Crossan, J. D. (1994). El Jesús de la historia. Vida de un campesino mediterráneo judío. Barcelona: Crítica.

Das, V. (1997). Sufferings, Theodicies, Disciplinary Practices. Appropriations International Social Science Journal, 49(154), 563-572.

Das V. (2008). Sufrimientos, Teodiceas, Prácticas Disciplinarias y Apropiaciones. En F. Ortega (ed.) Sujetos del dolor, Agentes de dignidad (pp. 437-458). Medellín: Universidad Nacional de Colombia.

Davidson, M. J. (1992). Angels at Qumran. A comparative Study of 1 Enoch 1-36, 72 108 and Sectarian Writing from Qumran. Sheffield: Sheffield Press.

Diez Macho, A. (1984). Apócrifos del Antiguo Testamento I-V. Madrid: Cristiandad.

Duch, Ll. (2002). Mito, interpretación y cultura. Barcelona: Herder.

Elior, R. (2004). The Three Temples. On the emergence of Jewish Mysticism. Oxford, Oregon: The Littman Library Liverpool University Press.

Elliot, M. (2002). Origins and functions of the Watchers Theodicy. Henoch Journal, 24, 63-75.

Frank, A. (2001). Can we research suffering? Qualitative Health Research, 11(3), 353-362.

García Martínez, F. (1997). The Dead Sea Scrolls. Study Edition I-II. Leiden: E. J. Brill.

Geertz, C. (2006). La interpretación de las culturas. Barcelona: Gedisa.

Hanson, P. (1977). Rebellion in Heaven, Azazel and Euhemeristic Heroes in 1 Enoch 6-11, Journal of Biblical Literature, 96(2), 195-233

Himmelfarb M., (1993). Ascent to Heaven in Jewish \&Christian Apocalypses. Oxford: Oxford Press.

Horsley, R. (2012). The prophet Jesus and the renewal of Israel. Moving beyond a diversionary debate. Grand Rapids, Michigan: W. Eerdmanns Publishing Company.

Laato, A. \& Moor, J. (2003). Theodicy in the world of the Bible. Leiden-Boston: Brill.

Mach, M. (1999). ¿From apocalypticism to Early Jewish mysticism?’. En J. J. Collins (Ed.), The Encyclopedy of Apocalypticism (pp. 229-264). New York: Continuum

Morgan, D. \& Wilkinson, I. (2001). The problem of suffering and the sociological task of theodicy. European Journal of Social Theory, 4(2), 199-214.

Nickelsburg, G. (1993). Jewish Literature. Between the Bible and the Misnah. London: SCM Press.

Nickelsburg, G. (1977). Apocalyptic and Myth in 1 Enoch 6-11. Journal of Biblical Literature, 96(3), 383-405. 
Ortega, F. (2008). Rehabitar la Cotidianidad. En F. Ortega (ed.) Sujetos del dolor, Agentes de dignidad (pp. 15-69) Medellín: Universidad Nacional de Colombia

Price, R. M. (1986). Illness Theodicies in the New Testament. Journal of Religion and Health, 25(4), 309-315.

Pritchard, J. (1969). Ancient near Easter texts relating to the Old Testament. Princeton: Princeton University Press.

Putt, B K. (1997). Indignation toward evil: Ricoeur and Caputo on a theodicy of protest. Philosophy Today, 40(3), 460-470.

Ramos T, R. (2012). Sociología del mal y teodicea en Las Formas Elementales de la Vida Religiosa de E. Durkheim. Politica y Sociedad, 49(2), 223-240.

Russell, D. S. (1964). The Method and Message of Jewish Apocalyptic. London: T\&T.

Sacchi, P. (2004). Historia del Judaismo en la época del Segundo Templo. Madrid: Trotta.

Sacchi, P. (1990). Jewish Apocalyptic and its History, Sheffield: Sheffield Academic Press.

Sarot, M. (2003). Theodicy and Modernity. An Inquiry into the Historicity of Theodicy. En A. Laato \& J. Moor (eds.), Theodicy in the world of the Bible. (pp. 1-26). Leiden: Brill.

Sharpe, J. L. (1973). The second Adam in the Apocalypse of Moses. The Catholic Biblical Quarterly, 35(1), 35-46.

Suter, D. (2005). Theodicy and the problem of the Intimate Enemy. En G. Boccaccini (ed.) Enoch and Qumran Origins. New Light on a Forgotten Connection. (pp. 329-335). Grand Rapids: Eerdmans

Vanderkam, J. (2010). Richteous one, Messiah, Chosen one, and the son of man in 1 Enoch 37-71. En J. H. Charlesworth (Ed.), The Messiah. Developments in Earliest Judaism and Christianity (pp. 169-191). Minneapolis: Fortres Press.

Weber M. (1978). Sociología de la religión. Buenos Aires: Pleyade.

Weber, M. (1997). Sociología de la religión. Madrid: Ed. Itsmo.

Weber M. (1998a). Ensayos sobre sociología de la religión (Vol. 1). Madrid: Taurus.

Weber M. (1998b). Ensayos sobre sociología de la religión (Vol. 2). Madrid: Taurus.

Weber M. (1998c). Ensayos sobre sociología de la religión (Vol. 3). Madrid: Taurus.

Weber, M. (2011). La Ética protestante y el Espiritu del Capitalismo. México: Fondo de Cultura Económica.

Weber M. (2014). Economía y sociedad. México: Fondo Cultura Económica.

Wolff, K. H. (1969). For a Sociology of Evil. Journal of Social Issues, 25(1), 111126. 